\title{
Epidemiology of lung cancer in northeast of Iran: A 25-year study of 939 patients
}

\author{
Mahta Salehi ${ }^{1}$, Maryam Salehi ${ }^{1}$, Soodabeh Shahidsales ${ }^{1}$, Golboo Goshayeshi $^{2}$, Maryam Emadzadeh ${ }^{3}$, \\ Mahdi Seilanian Toosi ${ }^{1}$, Seyed-Amir Aledavood ${ }^{1}$, Seyede Samaneh Hoseini ${ }^{4}$, Pardis Shojaei*4(D)
}

Received: 16 Jul 2018

Published: 7 Mar 2020

\begin{abstract}
Background: Lung cancer (LC) is a global public health priority. In this study, the epidemiology and current trends of primary LCs were investigated in northeast of Iran.

Methods: Demographic and pathologic records of primary LCs during 1985-2012 in Mashhad (capital of northeast of Iran) were reviewed. Data were obtained from archives of the largest referral oncologic hospital and the only private outpatient radiation-oncologic clinic in the region. To investigate trends, study duration was classified into 3 periods: 1985-1995, 1995-2005, and 2005-2012. Patients were placed in one of these 3 groups, based on the date of their pathologic diagnosis. Data were analyzed by SPSS 16 software. T test, chi-squared, and ANOVA tests were used for data analysis, and statistical significant level was set at $<0.05$.

Results: Among 939 cases with pathologic diagnosis of primary LC, male-to-female ratio was 2.36 . Mean \pm SD age at diagnosis was $61.47 \pm 12.01$ years in males and $58.45 \pm 12.75$ in females $(\mathrm{p}=0.001)$. Squamous cell carcinoma (SCC) was the most frequent pathologic subtype. Mean age at diagnosis and rate of smokers were unchanged during the study $(p=0.978$ and 0.153 , respectively). Relative frequency of leading pathologic subtypes changed in 3 intervals $(p<0.001)$ : it was increasing in adenocarcinoma and large cell carcinoma and decreasing in SCC and small cell lung cancer (SCLC). There were statistically significant differences in the mean age at diagnosis $(\mathrm{p}<0.001)$, rate of smokers $(\mathrm{p}<0.001)$, and male-to-female ratio $(\mathrm{p}=0.011)$ between leading pathologic subtypes.

Conclusion: Similar to universal picture, rate of adenocarcinoma in northeast of Iran was rising during recent decades, especially among younger patients, women, and nonsmokers. These trends are indicative of changes in exposures and smoking habits and reveal the need for regional studies in these contexts.
\end{abstract}

Keywords: Epidemiology, Lung cancer, Pathology, Smoking, Trend

Conflicts of Interest: None declared

Funding: Mashhad University of Medical Sciences

\section{*This work has been published under CC BY-NC-SA 1.0 license.}

Copyright $\odot$ Iran University of Medical Sciences

Cite this article as: Salehi M, Salehi M, Shahidsales S, Goshayeshi G, Emadzadeh M, Seilanian Toosi M, Aledavood SA, Hoseini SS, Shojaei P. Epidemiology of lung cancer in northeast of Iran: A 25-year study of 939 patients. Med J Islam Repub Iran. 2020 (7 Mar);34:17. https://doi.org/10.47176/mjiri.34.17

\section{Introduction}

Since 1985, lung cancer has been the most common and fatal cancer worldwide (1-3). Despite advances in the treatment of cancers, lung cancers still have poor prognosis,

Corresponding author: Dr Pardis Shojaei, shojaeip931@mums.ac.ir

1. Cancer Research Center, Mashhad University of Medical Sciences, Mashhad, Iran

2. Students Research Committee, Mashhad University of Medical Sciences, Mashhad, Iran

3. Clinical Research Unit, Faculty of Medicine, Mashhad University of Medical Sciences, Mashhad, Iran

4. Department of Community Medicine, Mashhad University of Medical Sciences, Mashhad, Iran commonly due to late diagnosis (1). Epidemiologic studies show shifts in the incidence rate of various pathologic subtypes of lung cancer over time which are attributed to

$\uparrow$ What is "already known" in this topic:

Lung cancer is the most common cancer worldwide. Global statistics and trend studies show shifts in the incidence of pathologic subtypes of this cancer which are parallel with the changes of people's demographic characteristics and smoking habits.

$\rightarrow$ What this article adds:

During the 25-year trend study of primary lung cancers in northeast of Iran, SCC and SCLCs were the leading pathologies, but rate of adenocarcinomas and large cell carcinomas were steadily rising. Male-to-female ratio of incident cases decreased steadily in the study period. Mentioned findings are consistent with global patterns. 
changes in exposure to risk factors, mainly smoking $(1,4$, $5)$. Any change in exposure to smoke will be reflected in lung cancer incidence and mortality 5 (6) to even 50 years (7) later. Other risk factors such as chemicals, air pollution, indoor radon, underlying lung diseases, and radiation along with genetic susceptibility may also lead to lung cancer (1, $4,8,9)$. More than $62 \%$ of the burden of tracheobronchial and lung (TBL) cancers in terms of DALYs (Disability-Adjusted Life Years) loss belongs to the developing world. This is substantially due to growing uncontrolled tobacco epidemic in these countries (3). In contrast, as a result of timely and successful tobacco control measures, prevalence of lung cancer in the developed world is decreasing or plateauing (10). Lung cancer in Iran is a public health problem with poor prognosis (11-13) and high burden (14): TBL cancers rank fifth in incidence and third in mortality of cancers in Iran (3).

Cancer surveillance is crucial for designing and implementation of preventive and control programs (15). Cancer registry in Iran dates back to1950s but there was not a systematic registration program to cover all regions of the country until 1984 (15). Pathologic-based cancer registration has been mandated in the country since 1984, but its coverage was low at first years of establishment (15). During recent years, population-based cancer registration has been gradually developing and covering the country, but previous statistics that are needed for trend analysis come from pathologic registrations with deficiencies in data gathering and low coverage (16).

Mashhad is the capital of northeast of Iran and the second metropolis of the country. Most patients with proven or doubtful cancer in northeast of Iran are referred to Mashhad. Population-based registration of lung cancers has been conducted in several metropolitan regions of Iran (other than Mashhad) since 1990s and trends have been studied in these areas (16). With the absence of local populationbased cancer registration in northeast of Iran and shortcomings of available pathologic-based data, especially in past years $(15,16)$, this study aimed to assess the epidemiology and trends of lung cancers in Mashhad from reliable records. Data were collected since 1985 when the national cancer registration program was in its first steps and its coverage was just $18 \%(15)$. Findings of this study will provide information about the profile and trends of lung cancer in northeast of Iran during recent decades that have not been studied beforehand.

\section{Methods}

In this cross sectional study, available records of morphologically-verified primary lung cancers during 1985-2012 in Mashhad (the capital of northeast and the second metropolis of Iran) were investigated. Data were obtained from 2 main referral sources: the largest referral oncologic hospital (Omid hospital) and the only private outpatient radiationoncology clinic in Mashhad. A record was assigned to each patient at first visit and patients' demographic information (gender, age, and history of smoking), diagnostic methods (clinical exploration, imaging findings, and pathologic/cytology diagnosis), and treatment measures (radiotherapy, chemotherapy, or other treatments) were available in the records from the first to the last visit at both centers. All records of lung cancers during the study period (including patients with proven primary lung cancers according to pathology/cytology reports) were reviewed. Patients with proven or doubtful lung metastasis (based on pathology, clinical and paraclinical findings) and those without pathology/cytology diagnosis were excluded. Information on the date of diagnosis, patients' demography (age, sex, and smoking history) and pathology of tumors were extracted. To warrant confidentiality of patients' information, their identities were concealed and each patient was assigned a code. Pathology/cytology reports were reviewed by 2 radiation-oncologic experts and were adapted to WHO Classification 2015 (17). To study the trends, patients were placed in one of the 3 following groups, based on the date of their pathologic diagnosis: 1985-1995, 1995-2005, and 20052012. Data were analyzed by SPSS 16 . Chi-squared test, ttest, and ANOVA (Tukey post-hoc test) were used for statistical analysis. Statistically significant level was set at $<$ 0.05 in this study.

\section{Results}

\section{General description}

In this study, available data of 939 cases with primary lung cancers in northeast of Iran during 1985-2012 were investigated. The mean $( \pm \mathrm{SD})$ age of participants at the time of diagnosis was $60.57( \pm 12.31)$ years, ranging from 17 to 95 , and $400(48.2 \%)$ cases were $\geq 65$. Of participants, $660(83.5 \%)$ were male, and male-to-female ratio was 2.36 . The mean $( \pm \mathrm{SD})$ age at diagnosis was $61.47( \pm 12.01)$ years in males and $58.45( \pm 12.75)$ years in females $(p=0.001)$. Data on smoking (tobacco and hookah) was only available in 555 cases, of whom $380(68.5 \%)$ were smokers. Of smokers, 293 (76.5\%) were male, $276(73 \%)$ reported cigarette smoking, and $161(42 \%)$ reported using hookah (some patients used both). Data on opium consumption could not be extracted from records. Female smokers used hookah nearly twice as male smokers: 63 (72\%) female smokers and 98 (37\%) male smokers reported using hookah.

\section{Demographic trends}

Table 1 demonstrates the demographic characteristics of cases according to their diagnosis period. The mean age at diagnosis and smoking rate were unchanged during the study period ( $\mathrm{p}=0.98$ and 0.15 , respectively). The rate of female incident cases increased during the study, especially since mid-90s. Rate of female smokers in patients was also increasing (Table 1). Figure 1 shows secular trends in the gender distribution of the study population and also smoker cases.

\section{Pathologic trends}

According to WHO classification 2015, pathologic diagnoses were categorized into 2 general groups of small cell lung cancers (SCLCs) and non-small cell lung cancers (NSCLCs), and the latter consisted of several subgroups. Frequencies of pathologic subtypes in this study are summarized in Table 2. The majority of cases were diagnosed with NSLCs (Table 2). Leading pathologic subtypes in this 
Table 1. Demographic characteristics of patients with primary lung cancers classified by year of diagnosis

\begin{tabular}{|c|c|c|c|c|}
\hline \multirow[t]{2}{*}{ Characteristics } & \multicolumn{3}{|c|}{ Period of diagnosis } & \multirow[t]{2}{*}{$\mathrm{P}$ value } \\
\hline & $1985-1995$ & $1995-2005$ & $2005-2012$ & \\
\hline Number of cases $(\%)$ & $213(22.7)$ & $481(51.2)$ & $245(26.1)$ & --- \\
\hline \multicolumn{5}{|l|}{ Gender } \\
\hline Male: N (\%) & $167(78.4)$ & $330(68.6)$ & $163(66.5)$ & \multirow[t]{2}{*}{$0.011^{2}$} \\
\hline Female: N (\%) & $46(21.6)$ & $151(31.4)$ & $82(33.5)$ & \\
\hline Male/female ratio & 3.63 & 2.18 & 1.99 & \\
\hline $\operatorname{Age}\left(\operatorname{Mean} \pm\right.$ SD $\left.^{1}\right)$ & $60.67 \pm 11.74$ & $60.57 \pm 12.24$ & $60.49 \pm 12.94$ & $0.978^{3}$ \\
\hline \multicolumn{5}{|l|}{ Smoking history } \\
\hline Yes: N $(\%)$ & $69(76.7)$ & $211(67.8)$ & $100(65)$ & \multirow[t]{2}{*}{$0.153^{2}$} \\
\hline No: $N(\%)$ & $21(23.3)$ & $100(32.2)$ & $54(35)$ & \\
\hline \multicolumn{5}{|l|}{ Smokers: } \\
\hline Male: N (\%) & $59(85.5)$ & $159(75.4)$ & $74(74)$ & \multirow[t]{3}{*}{$0.163^{2}$} \\
\hline Female: N (\%) & $10(14.5)$ & $52(24.6)$ & $26(26)$ & \\
\hline Male/female ratio & 5.9 & 3.06 & 2.84 & \\
\hline
\end{tabular}

2. Chi-squared test was used for data comparison.

3. ANOVA test was used for data comparison.

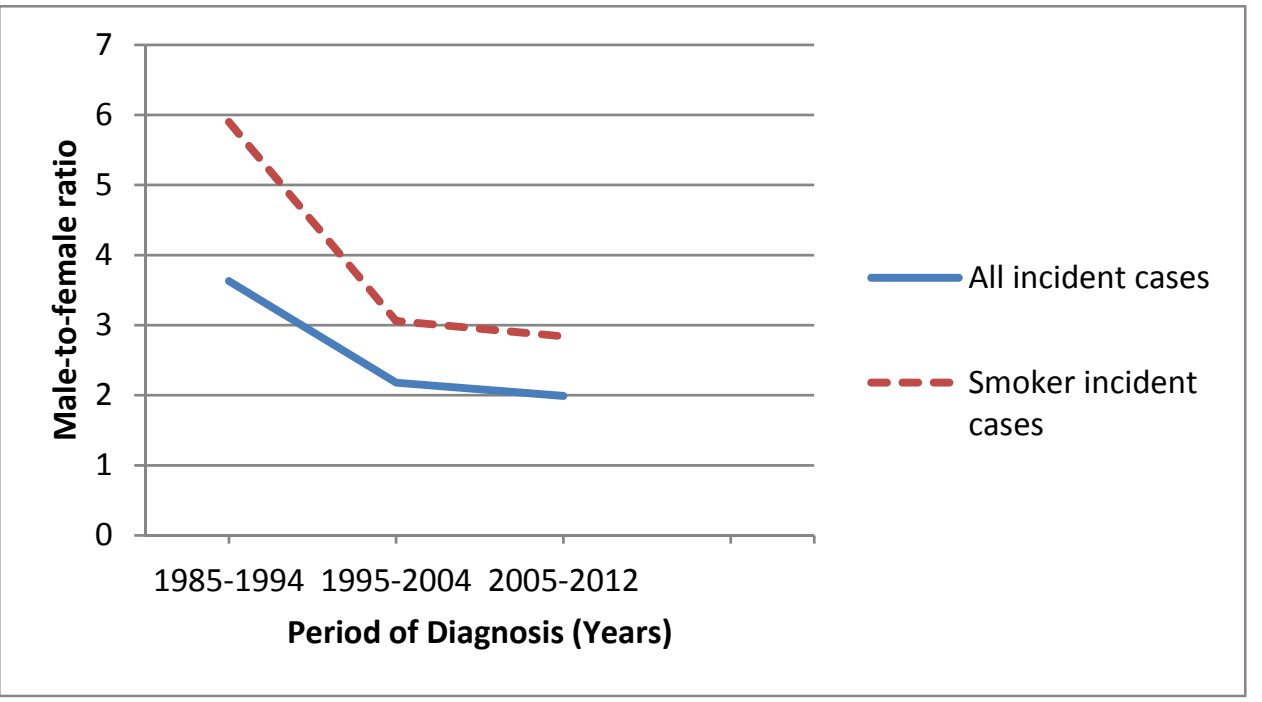

Fig. 1. Trends of gender distribution for all and smoker incident cases of primary lung cancers during the study

study were squamous cell carcinoma (SCC), adenocarcinoma, SCLCs, and large cell carcinoma (Table 2). In 124 $(13.2 \%)$ cases, definite pathology/cytology diagnosis of malignancy was made, but pathologic reports did not specify any diagnosis to be adapted to WHO classification. Changes of the relative frequencies of common lung cancer pathologies during the study period are demonstrated in Figure 2. Based on this figure, the rate of adenocarcinoma and large cell carcinoma were steadily rising. Demographic characteristics of patients with common pathologies are presented in Table 3. Special features in cases with adenocarcinoma were observed: mean age at diagnosis, male-to- female ratio, and rate of smokers were the lowest in these patients, compared to other common pathologies. More than half of cases with adenocarcinoma were nonsmoker, while the majority of the patients with SCC, SCLC, and large cell carcinoma were smoker (Table 3).

\section{Discussion}

In this 25-year study of primary lung cancers in northeast of Iran, there was a male predominance; however, gradual increase was observed in the rate of female patients and female smoker patients. These findings are consistent with global changes in the gender distribution of lung cancer and

\begin{tabular}{lc} 
Table 2. Frequency of pathologic subtypes of primary lung cancers in the study & \\
\hline WHO 2015 classification for pathologic subtypes & Number (\%) \\
\hline Small Cell Lung Cancers & $137(16.8)$ \\
Non-Small Cell Lung Cancers & $360(44.2)$ \\
Squamous cell carcinoma & $148(18.2)$ \\
Adenocarcinoma & $146(17.9)$ \\
Unclassified carcinomas & $11(1.3)$ \\
Large cell carcinomas & $6(0.7)$ \\
Carcinomas with pleomorphic, Sarcomatoid or sarcomatous elements & $3(0.4)$ \\
Carcinoids & $3(0.4)$ \\
Carcinomas of salivary gland types & $1(0.1)$ \\
Adenosquamous carcinomas & $815(100)$ \\
Total &
\end{tabular}




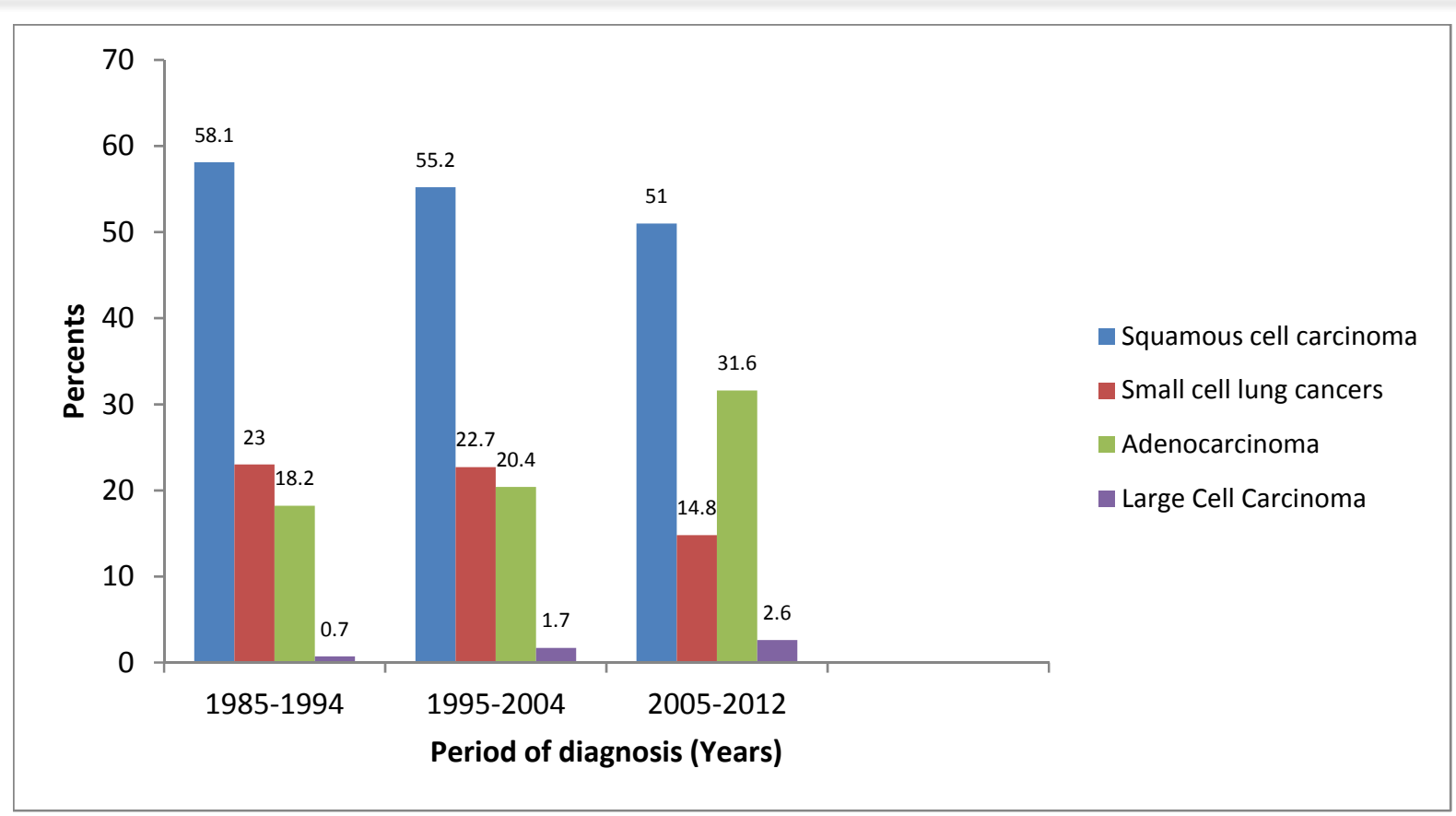

Fig. 2. Relative frequencies of common pathologic subtypes of primary lung cancers classified by their period of diagnosis

Table 3. Demographic characteristics of patients with 4 leading subtypes of lung cancers in the study

\begin{tabular}{|c|c|c|c|c|c|c|}
\hline \multirow[b]{2}{*}{ Patients' characteristics } & & \multicolumn{5}{|c|}{ Pathology } \\
\hline & & $\mathrm{SCC}^{1}$ & Adenocarcinoma & $\mathrm{SCLC}^{2}$ & Large cell carcinoma & $\mathrm{P}$ value \\
\hline Age $\left(\right.$ Mean $\left.\pm \mathrm{SD}^{3}\right)$ & & $63.18 \pm 10.64$ & $55.92 \pm 12.90$ & $58.91 \pm 13.07$ & $58.91 \pm 13.94$ & $<0.001^{4^{*}}$ \\
\hline \multirow[t]{3}{*}{ Age $\left(\right.$ Mean $\left.\pm \mathrm{SD}^{3}\right)$} & Male & $63.62 \pm 10.27$ & $56.90 \pm 13.52$ & $58.22 \pm 12.85$ & $60.89 \pm 14.48$ & --- \\
\hline & Female & $61.78 \pm 11.66$ & $54.27 \pm 11.72$ & $60.31 \pm 13.53$ & $50 \pm 8.48$ & \\
\hline & $P$ value ${ }^{5}$ & 0.29 & 0.15 & 0.29 & 0.34 & \\
\hline \multirow[t]{2}{*}{ Gender: N (\%) } & Male & $273(75.8)$ & $93(62.8)$ & $91(66.4)$ & $9(81.8)$ & $0.012^{6}$ \\
\hline & Female & $87(24.2)$ & $55(37.2)$ & $46(33.6)$ & $2(19.2)$ & \\
\hline Male/Female ratio & & 3.14 & 1.69 & 1.98 & 4.5 & --- \\
\hline \multirow{2}{*}{ Smoking: N (\%) } & Yes & $190(83)$ & $44(46.8)$ & $68(74)$ & $6(66.7)$ & $<0.001^{6}$ \\
\hline & No & $39(17)$ & $50(53.2)$ & $24(26)$ & $3(33.3)$ & \\
\hline
\end{tabular}

1. Squamous cell carcinom

2. Small cell lung cancers

3. Standard Deviation

4. ANOVA test was used to compare age between pathologic subgroups (*Post hoc test revealed statistically significant differences between $\mathrm{SCC}$ and $\mathrm{SCLC}$ ( $\mathrm{p}<0.001$ ),

between SCLC and adenocarcinoma ( $\mathrm{p}=0.032)$, and between SCC and adenocarcinoma $(\mathrm{p}<0.001)$

5. T-test was used to compare age between males and females in each pathologic subgroup.

6. Chi-squared test was used to compare smoking between pathologic subgroups.

smoking habits. Global statistics in 2012 showed that maleto-female ratio of lung cancers varied from 5.3 in Western Asia to 1.3 in Northern America (18). The global male predominance in lung cancer is mainly attributed to greater prevalence of smoking in men (6). However, the rate of lung cancer in women is gradually rising $(1,4,8,19-21)$. This rise has begun about 30 years ago in the developed world and later in developing countries (1) and is mainly due to changes in smoking habits of women (6). Globally, smoking epidemic in women has started and peaked later than men and its control also would be achieved later. Consequently, in many countries where lung cancer in men has been dropped (as a result of tobacco control programs), it is still increasing or in plateu among women $(10,22,23)$. Moreover, the rate of smoking among Iranian women is usually underestimated mainly due to social stigma (24). In addition, using hookah which is popular among Iranian women is not usually regarded in epidemiologic studies of lung cancers. The reasons for popularity of hookah may be its softer smoke, social acceptance, and misinterpretation of its safety (25). Besides hookah, other neglected risk factors for lung cancer with greater probability of exposure in Iranian women are passive smoking (about one third of nonsmoker women in Iran are passive smokers) (26) and cooking oil fumes at poorly ventilated kitchens (27). Thus, it is recommended to study various risk factors of lung cancer in Iran with emphasis on women.

The mean age at diagnosis of lung cancer in this study was 60.57 years. Other studies with comparable duration of follow-up in Greece and Thiland reported older incident ages $(21,28)$. Median age at diagnosis of lung cancers has been 70 years in USA in 2014 (29). In contrast, Study of incident primary lung cancers during three decades in India reported the mean age of 57.9 years (30). In the present study, $48.2 \%$ of cases were $\geq 65$ years. Similarly, the World report of 2002 on lung cancer demonstrated the same rate for people older than 65 years in developing countries (1). Compared to our study, reports from the developed world show older age at occurrence of primary lung cancers $(2$, 22). However, monographs from various regions of Iran showed both younger $(14,31)$ and older incident age of lung cancers $(32,33)$. As these studies are not 
methodologically consistent, further national studies are needed for making a reliable conclusion on the age of lung cancer occurence in Iran.

Age at diagnosis of lung cancer was unchanged over the study period. While a similar stable pattern in the last 3 decades has also been observed in another study in India (30), most trend studies during recent decades in developed countries show increasing age for lung cancer occurence (4, $21,34-38)$. Older incident age of lung cancer in developed countries can be attributed to greater life expectancy and population age structure in these areas (1). Additionally, preventive measures in developed countries have successfully controlled smoking; therefore, most lung cancers occur among older people who have not been under control programs $(1,2)$. Unfortunately, in Iran, regulations have not been successful to control smoking epidemic (24, 39).

In this study, female cases were younger than males. This pattern has also been reported in regional European studies (21) and its reason is not still clearly understood (22). Higher susceptibility of female genes to smoke carcinogens may be a reason $(40,41)$. In Asian countries, nonsmoker patients with lung cancer are younger than smoker patients (22) and this pattern can explain the younger age of our female patients, as the majority of them were nonsmokers.

The secular shift of common pathologic subtypes in this study is consistent with global picture $(1,7,38,42)$ and other studies in Iran (33). At the beginning of lung cancer epidemic, SCC and SCLC were the predominant global subtypes. However, the rate of SCLC has been decreasing since late 1980s (43), while adenocarcinoma has been increasing $(4,20,22)$ and the incidence of adenocarcinoma has even surpassed SCC and SCLCs in some countries (19, 44). Rate of adenocarcinoma first began to increase in the developed world and later in developing and Asian countries (22). There are several reasons for the global rise of adenocarcinoma. The first reason is the changes in tobacco products and consequent changes in people's smoking habits $(1,4)$. With the emergence of low tar, low nicotine, and filtered cigarettes in the last 4-5 decades (45), people inhaled smoke more deeply which resulted in concentration of smoke carcinogens in peripheral airways, predisposing them to lung adenocarcinoma $(1,7,30,38)$. Decreasing polycyclic aromatic hydrocarbons that caused $\mathrm{SCC}$ and increasing nitrites in cigarettes (as a contributor of adenocarcinoma) are other factors related to the recent pathologic shifts $(1,22)$. The second reason is that the rate of lung cancer among never-smokers is increasing (4) and never-smokers with lung cancer predominantly develop adenocarcinoma (22). The association between smoking and SCC and SCLC is greater than this association with adenocarcinoma and large cell carcinoma $(7,43)$. Explanations for the rising incidence of lung cancer in nonsmokers may be rises in passive smoking, risky occupational exposures, esterogen effects in women, and exposure to cooking fumes and viruses (22). The third reason may be that the required latency period for development of lung cancer after smoking is greater for adenocarcinoma compared to SCC and SCLC. Thus, adenocarcinoma emerges later than SCC and SCLC (22); and nowadays, after passing epidemics of SCC and SCLC, adenocarcima is in rise. Adenocarcinoma is generally more prevalent among females $(1,37)$ and this study found the lowest gender gap in the frequency of this subtype.

In the present study, among the SCLCs, 74\% were smokers, while this rate was more than $90 \%$ in most studies (1). This difference can be due to underreporting of smoking history in our patients. Smoking history was only based on patients' self report, which is not bias-free. This study only relied on pathologic diagnoses, and compared to population-based studies, underestimated the frequency of patients. In addition, old pathologic reports were not very precise, and in some cases there was not a decissive diagnosis. Ongoing National Population-based Cancer Registry will provide accurate and comprehensive statistics in future studies.

\section{Conclusion}

Study of primary lung cancers in northeast of Iran during the last 3 decades revealed growing incidence of adenocarcinoma, increasing rate of female cases, and female smokers. Adenocarcinoma, in comparison with SCC and SCLCs, was more prevalent among younger patients, women and nonsmokers. Preventive programs, especially ongoing tobacco and hookah restriction measures, need to be revised in this area. Also, further studies on risk factors of lung cancers in this region with emphasis on women are recommended.

\section{Funding}

This article is the result of a thesis and was supported by the Vice Chancellery of Research, Mashhad University of Medical Sciences.

\section{Ethical Considerations}

This work was approved by the Ethics Committee of Mashhad University of Medical Sciences, with ethical code of: IR.MUMS.fm.REC.1395.1.

\section{Acknowledgements}

The authors would like to thank the Clinical Research Development Unit of Ghaem Hospital, Mashhad, Iran, for its collaboration.

\section{Conflict of Interests}

The authors declare that they have no competing interests.

\section{References}

1. Youlden DR, Cramb SM, Baade PD. The international epidemiology of lung cancer: geographical distribution and secular trends. J Thorac Oncol. 2008;3(8):819-31.

2. Dela Cruz CS, Tanoue LT, Matthay RA. Lung Cancer: epidemiology, etiology, and prevention. Clin Chest Med. 2011;32(4):605-44.

3. Global Burden of Disease Cancer Collaboration. The Global Burden of Cancer 2013. JAMA Oncol. 2015;1(4):505-27.

4. Debieuvre D, Oster JP, Riou R, Berruchon J, Levy A, Mathieu JP, et al The new face of non-small-cell lung cancer in men: Results of two French prospective epidemiological studies conducted 10 years apart. Lung Cancer. 2016;91:1-6.

5. Torre LA, Siegel RL, Jemal A. Lung cancer statistics. Adv Exp Med Biol. 2016;893:1-19. 
6. Mowls DS, Campbell J, Beebe LA. Race and gender disparities in lung cancer incidence rates, 2001-2010. J Okla State Med Assoc. 2015;108(11):482-7.

7. Riaz SP, Lüchtenborg M, Coupland VH, Spicer J, Peake MD, Møller $\mathrm{H}$. Trends in incidence of small cell lung cancer and all lung cancer. Lung Cancer. 2012;75(3):280-4.

8. Schwartz AG, Cote ML. Epidemiology of lung cancer. Adv Exp Med Biol. 2016;893:21-41.

9. Hori M, Tanaka H, Wakai K, Sasazuki S, Katanoda K. Secondhand smoke exposure and risk of lung cancer in Japan: a systematic review and meta-analysis of epidemiologic studies. Jpn J Clin Oncol. 2016;46(10):942-51.

10. Islami F, Torre LA, Jemal A. Global trends of lung cancer mortality and smoking prevalence. Transl Lung Cancer Res. 2015;4(4):327-38.

11. Jamaati H, Baghaei P, Sharifianfard M, Emami H, Najmi K, Seifi S, et al. Risk factors for lung cancer mortality in a referral center. Asian Pac J Cancer Prev. 2016;17(6):2877-81.

12. Abazari M, Gholamnejad M, Roshanaei G, Abazari R, Roosta Y, Mahjub H. Estimation of survival rates in patients with lung cancer in west Azerbaijan, the northwest of Iran. Asian Pac J Cancer Prev. 2015;16(9):3923-6

13. Zahir ST, Mirtalebi M. Survival of patients with lung cancer, Yazd, Iran. Asian Pac J Cancer Prev. 2012;13(9):4387-91.

14. Mohagheghi MA, Mousavi-Jarrahi Y, Mosavi-Jarrahi A. Cost of care for lung cancer in the first year after diagnosis in Iran. Asian Pac J Cancer Prev. 2011;12(4):1013-5.

15. Etemadi A, Sadjadi A, Semnani S, Nouraie SM, Khademi H, Bahadori M. Cancer registry in Iran: a brief overview. Arch Iran Med. 2008;11(5):577-80

16. Vardanjani HM, Heidari M, Hadipour M. Can we rely on GLOBOCAN and GBD cancer estimates? Case study of lung cancer incidence and mortality Rates and trends in Iran. Asian Pac J Cancer Prev. 2016;17(7):3265-9.

17. Travis WD, Brambilla E, Nicholson AG, Yatabe Y, Austin JHM, Beasley MB, et al. The 2015 World Health Organization classification of lung tumors: impact of genetic, clinical and radiologic advances since the 2004 classification. J Thorac Oncol. 2015;10(9):1243-60.

18. Rafiemanesh H, Mehtarpour M, Khani F, Hesami SM, Shamlou R, Towhidi F, et al. Epidemiology, incidence and mortality of lung cancer and their relationship with the development index in the world. J Thorac Dis. 2016;8(6):1094-102.

19. Cheng TY, Cramb SM, Baade PD, Youlden DR, Nwogu C, Reid ME. The international epidemiology of lung cancer: latest trends, disparities, and tumor characteristics. $\mathrm{J}$ Thorac Oncol. 2016;11(10):1653-71

20. Denton EJ, Hart D, Wainer Z, Wright G, Russell PA, Conron M. Changing trends in diagnosis, staging, treatment and survival in lung cancer: comparison of three consecutive cohorts in an Australian lung cancer centre. Intern Med J. 2016;46(8):946-54

21. Kontakiotis T, Manolakoglou N, Zoglopitis F, Iakovidis D, Sacas L, Papagiannis A, et al. Epidemiologic trends in lung cancer over two decades in Northern Greece: an analysis of bronchoscopic data. Monaldi Arch Chest Dis. 2009;71(4):147-52.

22. Park JY, Jang SH. Epidemiology of lung cancer in Korea: recent trends. Tuberc Respir Dis (Seoul). 2016;79(2):58-69.

23. Hitchman SC, Fong GT. Gender empowerment and female-to-male smoking prevalence ratios. Bull World Health Organ. 2011;89(3):195202.

24. Meysamie A, Ghaletaki R, Haghazali M, Asgari F, Rashidi A, Khalilzadeh O, et al. Pattern of tobacco use among the Iranian adult population: results of the national Survey of Risk Factors of NonCommunicable Diseases (SuRFNCD-2007). Tob Control. 2010;19(2):125-8.

25. Tee GH, Hairi NN, Nordin F, Choo WY, Chan YY, Kaur G, et al. Systematic review on international practices in controlling waterpipe tobacco smoking. Asian Pac J Cancer Prev. 2015;16(9):3659-65.

26. Salimzadeh H, Najafipour H, Mirzaiepour F, Navadeh S, ShadkamFarrokhi M, Mirzazadeh A. Prevalence of active and passive smoking among adult population: findings of a population-based survey in Kerman (KERCADRS), Iran. Addict Health. 2016;8(1):16-24.

27. Xue Y, Jiang Y, Jin S, Li Y. Association between cooking oil fume exposure and lung cancer among Chinese nonsmoking women: a metaanalysis. Onco Targets Ther. 2016;9:2987-92.

28. Sriplung H, Yeesoonsang S, McNeil E, Bilheem S. The use of a multiple imputation method to investigate the trends in Histologic types of lung cancer in Songkhla province, Thailand, 1989-2013. BMC Cancer. 2016;16:389.

29. DeSantis CE, Lin CC, Mariotto AB, Siegel RL, Stein KD, Kramer JL, et al. Cancer treatment and survivorship statistics, 2014. CA Cancer J Clin. 2014;64(4):252-71.

30. Singh N, Aggarwal AN, Gupta D, Behera D, Jindal SK. Unchanging clinico-epidemiological profile of lung cancer in north India over three decades. Cancer Epidemiol. 2010;34(1):101-4.

31. Tarrahi MJ, Mehrabani D, Khademolhosseini F, Amini M, Masoumi SJ, Julaee H, et al. Lung cancer occurrence in Southern Iran. J Res Med Sci. 2009;14(2):139-40.

32. Hajmanoochehri F, Mohammadi N, Zohal MA, Sodagar A, Ebtehaj M. Epidemiological and clinicopathological characteristics of lung cancer in a teaching hospital in Iran. Asian Pac J Cancer Prev. 2014;15(6):2495-500.

33. Almasi Z, Salehiniya H, Amoori N, Enayatrad M. Epidemiology characteristics and trends of lung cancer incidence in Iran. Asian Pac J Cancer Prev. 2016;17(2):557-62.

34. O'Rourke MA, Feussner JR, Feigl P, Laszlo J. Age trends of lung cancer stage at diagnosis. Implications for lung cancer screening in the elderly. JAMA. 1987;258(7):921-6

35. Linares I, Molina-Portillo E, Expósito J, Baeyens JA, Suárez C, Sánchez MJ. Trends in lung cancer incidence by histologic subtype in the south of Spain, 1985-2012: a population-based study. Clin Transl Oncol. 2016;18(5):489-96.

36. Grimsrud TK, Skaug HK, Larsen IK. Lung cancer - changes in incidence by gender, age and county of residence 1984-2013. Tidsskr Nor Laegeforen. 2015;135(20):1844-9.

37. Zhang R, Zhang Y, Wen F, Wu K, Zhao S. Analysis of pathological types and clinical epidemiology of 6,058 patients with lung cancer Zhongguo Fei Ai Za Zhi. 2016;19(3):129-35.

38. Zheng T, Holford TR, Boyle P, Chen Y, Ward BA, Flannery J, et al. Time trend and the age-period-cohort effect on the incidence of histologic types of lung cancer in Connecticut, 1960-1989. Cancer. 1994;74(5):1556-67.

39. Ghasemian A, Rezaei N, Saeedi Moghaddam S, Mansouri A, Parsaeian M, Delavari A, et al. Tobacco smoking status and the contribution to burden of diseases in Iran, 1990-2010: findings from the Global Burden of Disease Study 2010. Arch Iran Med. 2015;18(8):493-501.

40. Ryberg D, Hewer A, Phillips DH, Haugen A. Different susceptibility to smoking-induced DNA damage among male and female lung cancer patients. Cancer Res. 1994;54(22):5801-3.

41. Radzikowska E, Głaz P, Roszkowski K. Lung cancer in women: age, smoking, histology, performance status, stage, initial treatment and survival. Population-based study of 20561 cases. Ann Oncol. 2002;13(7):1087-93.

42. Dodds L, Davis S, Polissar L. A population-based study of lung cancer incidence trends by histologic type, 1974-81. J Natl Cancer Inst. 1986;76(1):21-9.

43. Govindan R, Page N, Morgensztern D, Read W, Tierney R, Vlahiotis $\mathrm{A}$, et al. Changing epidemiology of small-cell lung cancer in the United States over the last 30 years: analysis of the surveillance, epidemiologic, and end results database. J Clin Oncol. 2006;24(28):4539-44.

44. Costa G, Thuler LC, Ferreira CG. Epidemiological changes in the histological subtypes of 35,018 non-small-cell lung cancer cases in Brazil. Lung Cancer. 2016;97:66-72.

45. Meza R, Meernik C, Jeon J, Cote ML. Lung cancer incidence trends by gender, race and histology in the United States, 1973-2010. Chellappan SP, ed. PLoS One. 2015;10(3):e0121323. 